International Journal of Engineering \& Technology, $7(4.30)(2018) 116-120$
International Journal of Engineering \& Technology
Website: $w w w . s c i e n c e p u b c o . c o m / i n d e x . p h p / I J E T$
Research paper

\title{
Recycled Concrete Aggregates as a Filter for Removal of Phosphorus in Synthetic Wastewater
}

\author{
Norwardatun Abd Roni ${ }^{1 *}$, Suraya Hani Adnan ${ }^{2}$, Rafidah Hamdan ${ }^{3}$ \\ ${ }^{1,2,3}$ Department of Engineering Technology, \\ Universiti Tun Hussein Onn Malaysia, \\ 86400 Batu Pahat, Johor. \\ * Corresponding authors E-mail: norwardatun93@gmail.com
}

\begin{abstract}
This paper assesses of recycled concrete aggregates as a filter for removal of phosphorus in synthetic wastewater. Recycled concrete aggregate used as a filter system emerged as an alternative technology for phosphorus removal. This can overcome the problem of construction site waste by converting the waste into something valuable products. Thus, this study aim to determine the percentage of Phosphorus removal by using two different size of Recycled Concrete Aggregate which is ( $5 \mathrm{~mm}$ to $10 \mathrm{~mm}$ ) and (25 mm to $30 \mathrm{~mm}$ ). A total of five vertical recycled concrete aggregate filter laboratory scale was design using recycled concrete aggregate and five different concentration of synthetic wastewater which is $10-50 \mathrm{mg} / \mathrm{L}$ was prepared. Samples were taken from the influent and effluent filters to be tested once a week, and analyzed to determine the value of $\mathrm{pH}$ and the percentage of Phosphorus removal (\%). RCA was analyzed using Scanning Electron Microscopy (SEM) and Energy-dispersive X-ray spectroscopy (EDX) testing to determine chemical composition. Results shows that RCA is highly contained with Aluminium, Calcium and Magnesium elements that enhanced the phosphorus adsorption. The RCA with size $5 \mathrm{~mm}$ to $10 \mathrm{~mm}$ and synthetic wastewater $10 \mathrm{mg} / \mathrm{L}$ display high potential in removing Phosphorus with $99.54 \%$ removal at $\mathrm{pH}$ 9.77. The lower concentration of synthetic wastewater, smaller size of RCA and higher pH have slightly better Phosphorus removal efficiency. Thus, RCA has a potential in removing Phosphorus from synthetic wastewater.
\end{abstract}

Keywords: Chemical Characteristic; Phosphorus; Physical Characteristic; Recycled Concrete Aggregates; Synthetic Wastewater.

\section{Introduction}

Phosphorus $(\mathrm{P})$ is a main nutrient element plants growth in natural water system. However, excessive P loads to water bodies from industrial, agricultural, household wastes may cause the overgrowth of aquatic plants or algae which accelerate the depletion of dissolved oxygen (DO) in waters, and leading to serious eutrophication problems. In developing countries, approximately $75 \%$ of domestic wastewater is released to the environment without treatment [1]. Ayaz et al., [2] reported that eutrophication in receiving water bodies may occur when concentration of phosphorus was 6 $\mathrm{mg} / \mathrm{L}$. Therefore, proper treatment to remove phosphorus from domestic wastewater to achieve the admissible level for natural systems is needed. Nowadays, construction and demolition (C\&D) activities shows a growing trend for several years. High cost waste disposal and pollution will occur if the management of solid waste in construction not disposed in a proper method. Thus, to promote sustainable of natural resources and reduced disposal of demolition waste, recycling of concrete is a significant alternative method. Recycled concrete aggregate that has been crushed for selected size was used in this study to investigate its performance as an effective filter for removal of $P$.

For water treatment, removal of $\mathrm{P}$ in wastewater is a common procedure. Improving water quality is the aim for wastewater treatment. There are many types of conventional methods that have been used for removing of $\mathrm{P}$. Phosphate reaction with chemicals can be removed immediately from water.
However, the use of chemicals increases the cost of wastewater treatment [3]. Therefore, this study was conducted to find the appropriate method of eliminating phosphorus in a filter system using recycled concrete aggregate as it is low cost and environmentally friendly. The aim of this study is to determine percentage removal of Phosphorus by using recycled concrete aggregate as filter in synthetic wastewater.

According to [4], the important factors that need to be considered in designing a filter are the selection of the filter material itself. The utilization of easily available and low-cost materials has been widely demonstrated by previous study in removing phosphorus including limestone, fly ash, iron oxide, steel slag and blast furnace slag [5]. Therefore, a detailed study of filter media capabilities for the removal of phosphorus is essential.

There are several factors which affect the performance removal of phosphorus such as $\mathrm{pH}$, temperature, concentration of metallic salt, and many more. $\mathrm{pH}$ values of the influents are identified to contribute important effect on removal of phosphorus. In general, removal of phosphorus favors basic state where adsorption will occur at low $\mathrm{pH}$ and Calcium will precipitate at high $\mathrm{pH}$ value. However, the outcome of $\mathrm{pH}$ can be dissimilar with respect to chemical composition of the element. When the element has very great percentage of Calcium $(\mathrm{Ca})$, phosphate will be formed at high $\mathrm{pH}$ value and precipitation control the removal of mechanism. Contrariwise, when the element contains high percentage of iron $(\mathrm{Fe})$, adsorption into Fe will dominate the removal of phosphorus mechanism at acidic range [6]. Nonetheless, the main phosphorus removal mechanism in rock filters are through adsorption and precipitation with metal $\mathrm{Ca}$ and $\mathrm{Fe}$. 
Unaerated system and aerated system vary in the starter of oxygen into the systems throughout the aeration process. Below aerobic conditions, Calcium and Aluminium adsorb on the surface of adsorbent which be able to be the adsorption site for removal of phosphorus however phosphate are precipitated out with $\mathrm{Fe}$ ions. Besides that, high dissolved oxygen in aerated conditions effects much more carbon dioxide to be exposed to the atmosphere therefore produce slight carbonic acid. This outcomes in the increase in $\mathrm{pH}$ levels in the system [7]. In this study, unaerated system has been chosen due to its performance were slightly better compared to aerated system which is the system can removed 76-98\% of Phosphorus while for aerated system the removing of Phosphorus is (66-95\%) [6]. It is evidently seen that unaerated system perform better at removing of phosphorus [6]. Hence, unaerated system chosen in this study. Then again, the size of RCA also influenced on the removal of phosphorus. From previous study [8], stated that for different size of RCA, it shows that smaller size of RCA act as the best filter media in removing Phosphorus which is for (6699\%) percentage removal of Phosphorus between sizes of RCA (5-35 mm). The initial concentration of synthetic wastewater chosen from (10-50 mg/L).

\section{Experimental Study}

In this study, Recycled Concrete Aggregates (RCA) was collected from concrete cube waste at Heavy Structure Laboratory, Universiti Tun Hussein Onn Malaysia (UTHM). Then the concrete cube waste were crushed by using the crushing machines (Concrete Crusher A35399), Malaysia in order to produce Recycled Concrete Aggregates (RCA). Next aggregates were being sieves with size $(5 \mathrm{~mm}$ to $30 \mathrm{~mm}$ ) which is the size used in this study by test sieve (British Standard sieve BS410/1986) using a shaker, Endecotts Lombard Rd. London, model Sw193BR, England.

\subsection{Filter column}

In this study, the lab scale of vertical Recycled Concrete Aggregates Filter (VARCAF) was developed to investigate the removing of phosphorus from synthetic wastewater in this study. VAR$\mathrm{CAF}$ was designed in cylindrical shape. In this study, there are five VARCAF was design and placed at Wastewater Engineering Laboratory, Faculty of Civil and Environmental Engineering, Universiti Tun Hussein Onn Malaysia (UTHM). The VARCAF was designed with the inner diameter of $150 \mathrm{~mm}, 5 \mathrm{~mm}$ of thickness and total height is $420 \mathrm{~mm}$ made from Perspex material. Figure 1 shows filter design system. The VARCAF designed based on Hydraulic Loading Rate. Based on the study by William and Swanson [9], HLR starts from range of 0.06 to 0.34 day $^{-1}$. For the warm climates like Malaysia, HLR range is lower compared to another country which are calmer climates. Based on this situation, this study takes 0.06 for the value range of HLR as the initial trial.

\subsection{Synthetic wastewater}

The synthetic wastewater was prepared by using Potassium Dihy drogen Phosphate $\left(\mathrm{KH}_{2} \mathrm{PO}_{4}\right)$. For the preparation of synthetic wastewater, 4.391g of $\mathrm{KH}_{2} \mathrm{PO}_{4}$ was weighed and filled into a $1 \mathrm{~L}$ volumetric flask. Then, distilled water was added into the volumetric flask up to $1 \mathrm{~L}$ in volume to produce a phosphorus concentration of $1000 \mathrm{mg} / \mathrm{L}$. Then, the mixture was mixed thoroughly. The synthetic wastewater was prepared in five different initial concentrations namely, $10 \mathrm{mg} / \mathrm{L}, 20 \mathrm{mg} / \mathrm{L}, 30 \mathrm{mg} / \mathrm{L}, 40 \mathrm{mg} / \mathrm{L}$ and $50 \mathrm{mg} / \mathrm{L}$. In order to produce different initial concentrations of phosphorus in synthetic wastewater, the stock solution was diluted using distilled water.

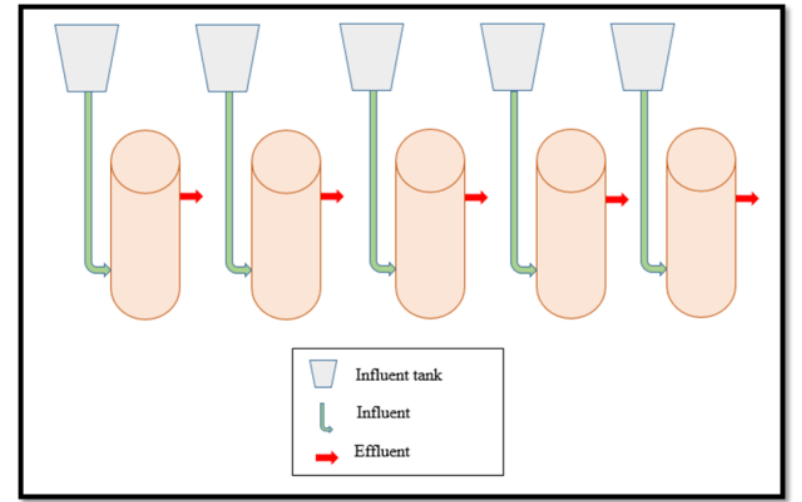

Fig.1: Schematic diagram of the layout of the lab-scale vertical unaerated recycled concrete aggregate filter system

\subsection{Scanning Electron Microscopy and Energy disper- sive X-ray spectroscopy}

The testing was conducted according to ASTM C1723-16, Standard Guide Using Scanning Electron Microscopy by using SEM machine and the EDX testing machine (Oxford Instruments XMax). RCA samples were placed in the oven immediately after collection from the experiment station to dry for 24 hours at $105^{\circ} \mathrm{C}$ before they were allowed to cool in a desiccator. The RCA samples were then crushed to about $0.5 \mathrm{~cm}$ in size using a mortar and a pestle. The crushed samples were soaked in acetone in an ultrasonic shaker for a few minutes to remove loose material on the surface. Later, the cleaned samples were dried on a hot plate at 110 degree celsius with cold setting glue. Finally, the mounted samples were coated with a thin layer using an SEM machine (Oxford Instruments X-Max). This test was conducted at the University Lab Management Unit, Universiti Teknologi Malaysia, Skudai.

\subsection{Analysis method}

The samples were analyzed using WESTCO Discrete Analyzer method, model Smartchem 200, France. The phosphorus removal efficiency was obtained by determining the removal percentage of the phosphorus by using formula:

$$
\begin{gathered}
\text { Removal of phosphorus (\%): influent (mg/L) - effluent (mg/L) / } \\
\text { influent (mg/L) }
\end{gathered}
$$

\section{Result and Discussion}

\subsection{Scanning Electron Microscopy (SEM) and Energy dispersive X-ray spectroscopy (EDX) of RCA}

SEM and EDX testing were used in this study in order to examine phosphorus distribution on the RCA surface and in sediment samples. SEM and EDX testing for fresh surfaces of the RCA samples are shown in figure 2 and fresh blast furnace slag in figure 3 while figure 4 and 5 shows the SEM and EDX testing after treatment. The surface of the RCA sample is covered by loosely bonded cement paste and considerably amount of porous fine particles. Moreover, from the SEM/EDX analysis, the most abundant minerals on a fresh RCA surface was founded to be oxygen, calcium and silica. The result indicated the highest element in RCA is oxygen which is $46.20 \%$ follows by calcium which is $23.40 \%$ and $11.20 \%$ of silica.

As we know, cement paste contains high amount of Calcium [8]. This is due to the higher calcium content, the higher the ability for removing phosphorus. Besides the RCA also contain aluminium and magnesium whereas this element enhances phosphorus ad- 
sorption. After two months in the filter system, phosphorus can be seen on the surface of RCA samples after being examined by SEM/EDX testing. Figures 4.4 show the presence of phosphorus on the surface of RCA through EDX mapping and the spectrum analysis of surface RCA samples after a two-month period of the treatment. Figure 4.5 shows the SEM and EDX test for Blast Furnace Slag (BFS) samples. The presence of phosphorus on the surface of RCA is $2.60 \%$. It was similar result by Hamdan and Mara, for BFS sample which is $2.20 \%$ presence of Phosphorus. Hamdan and Mara [7], state that phosphorus rich oxides was formed after the effluent from primary facultative pond underwent further treatment in the BFS filter. These findings demonstrate that BFS and RCA has a high capacity for adsorbing phosphorus from wastewater which same took place on the BFS surface and RCA surface. The RCA was encompassed of $36.60 \%$ of calcium oxide that was stated from previous study by [8] while [7] state that the BFS was comprised of $39.97 \%$ of calcium oxide. Therefore, the adsorption of phosphorus to calcium oxide could have been the key removal mechanism for phosphorus in the RCA filter and BFS filter. This is because calcium and aluminium adsorb on the surface of adsorbents to become the adsorption site for the removal of phosphorus.

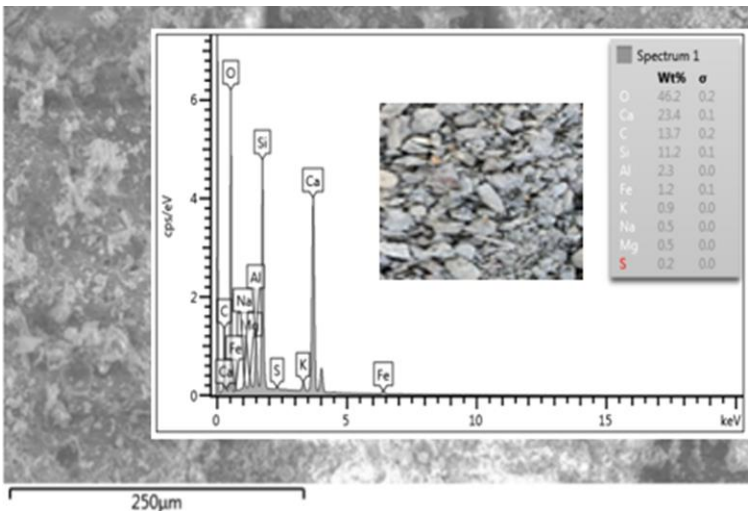

Fig. 2: EDX testing for fresh Recycled concrete aggregate

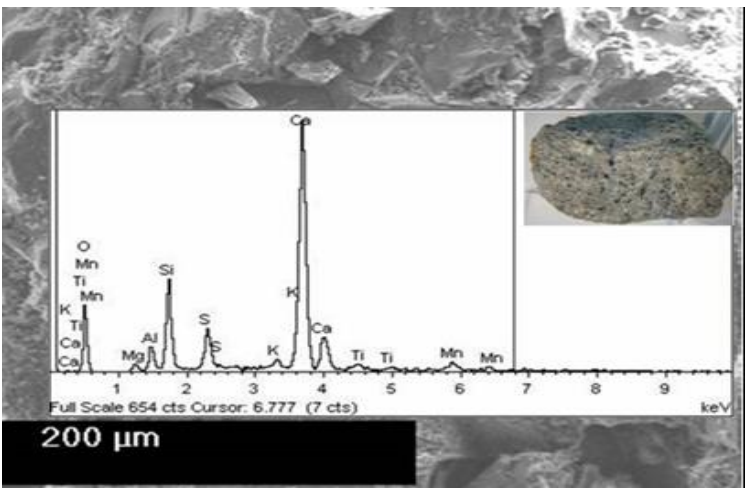

Fig. 3: EDX testing for fresh BFS [7]

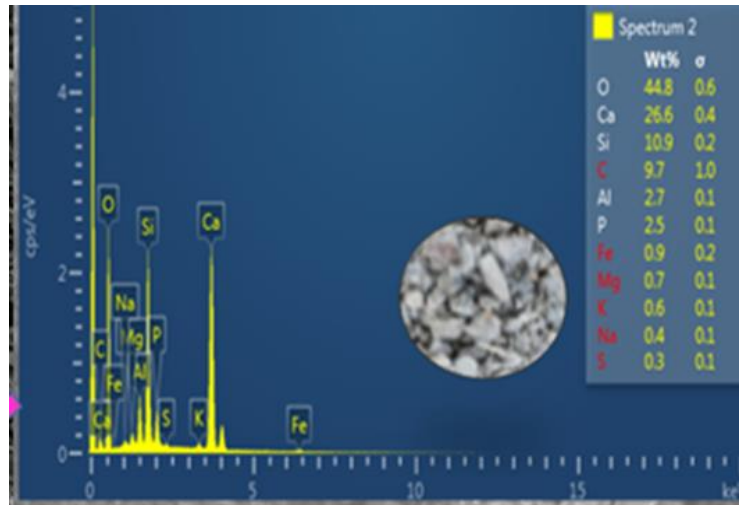

Fig. 4: SEM micrographs and EDX spectra of RCA surface samples over treatment period in the vertical Recycled Concrete Aggregate filter

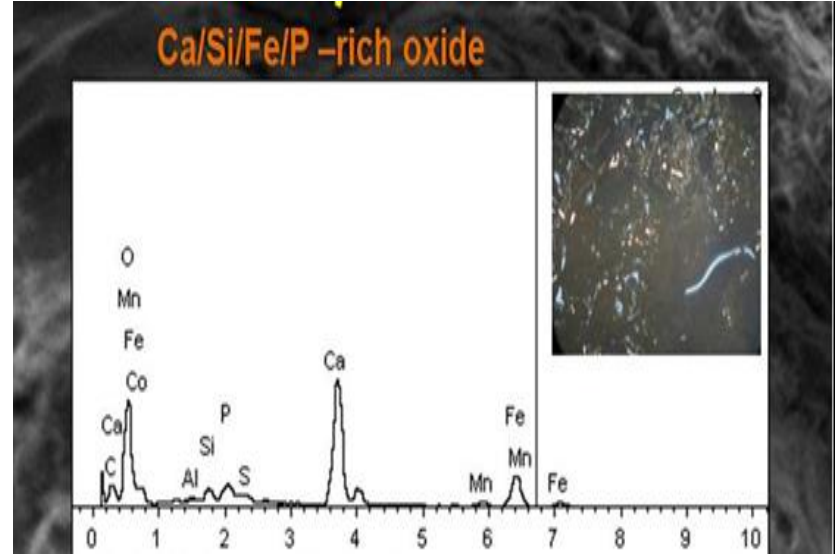

Fig. 5: SEM micrographs and EDX spectra of BFS surface samples over treatment period in the aerated BFS filter

\subsection{Percentage of phosphorus removal efficiency}

This section discussed on data and analysis on percentage of Phosphorus removal. Figure 6 shows graph of percentage of Phosphorus removal with different concentration of synthetic wastewater for RCA size $(5-10 \mathrm{~mm})$ and $(25-30 \mathrm{~mm})$ with five different concentration of synthetic wastewater. For RCA size (5$10 \mathrm{~mm}$ ), the percentage of Phosphorus removal in initial concentration $10 \mathrm{mg} / \mathrm{L}$ is $99.54 \%$, then $76.92 \%$ for initial concentration $20 \mathrm{mg} / \mathrm{L}$ while $74.94 \%$ for initial concentration $30 \mathrm{mg} / \mathrm{L}, 69.91 \%$ for initial concentration $40 \mathrm{mg} / \mathrm{L}$ and lastly $67.60 \%$ for initial concentration $50 \mathrm{mg} / \mathrm{L}$. Next, for RCA size $(25-30 \mathrm{~mm})$, the percentage of Phosphorus removal in initial concentration $10 \mathrm{mg} / \mathrm{L}$ is $94.49 \%$, then $68.95 \%$ for initial concentration $20 \mathrm{mg} / \mathrm{L}$ while $67.89 \%$ for initial concentration $30 \mathrm{mg} / \mathrm{L}, 66.42 \%$ for initial concentration $40 \mathrm{mg} / \mathrm{L}$ and lastly $66.25 \%$ for initial concentration 50 $\mathrm{mg} / \mathrm{L}$.

The highest percentage of Phosphorus removal is $99.54 \%$ which is in concentration $10 \mathrm{mg} / \mathrm{L}$ for RCA size $5 \mathrm{~mm}$ to $10 \mathrm{~mm}$ while the lowest percentage of Phosphorus removal is $66.25 \%$ which is in concentration $50 \mathrm{mg} / \mathrm{L}$ for RCA size $25 \mathrm{~mm}$ to $30 \mathrm{~mm}$. Commonly it can be seen that the percentage of Phosphorus removal decreasing as concentration of synthetic wastewater increasing. From the graph, it defined that the percentage of phosphorus removal decreasing as initial concentration of synthetic wastewater increasing. It was similar due to the outcomes from Wood and Atamney [10] where (80-90\%) of initial Phosphorus where absorbed by Laterite when applying concentrations $(10-25 \mathrm{mg} / \mathrm{L})$ and $60 \%$ of initial Phosphorus absorbed when higher concentration applied. Regarding to [11], the adsorption capacity increased linearly with the initial concentration from $(5-30 \mathrm{mg} / \mathrm{L})$, but the amount of Phosphorus removed reach maximum at an initial concentration of $15 \mathrm{mg} / \mathrm{L}$. This suggest that removal of Phosphorus not suitable at higher initial concentration. The uptake capacity of phosphorus was predominantly affected by the size of the medium used. This is because the smaller the size of the medium, the greater the surface available for calcium oxide dissolution [12] 


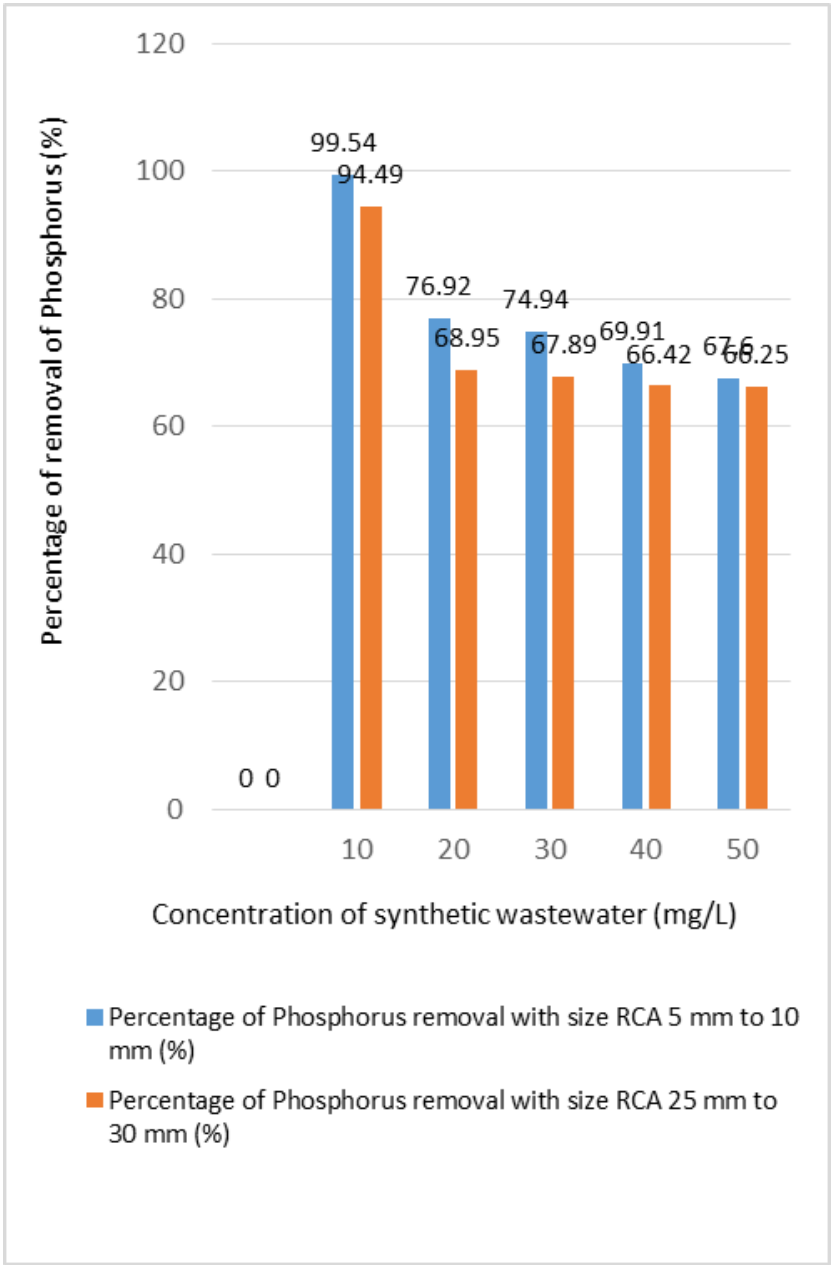

Fig. 6: Graph of percentage of Phosphorus removal with different size of RCA versus different concentration of synthetic wastewater

\subsection{Percentage removal of Phosphorus due to $\mathrm{pH}$}

The $\mathrm{pH}$ value is the concentration of the hydrogen ion contained in a solution [13]. Figure 7 shows graph percentage of Phosphorus removal versus $\mathrm{pH}$ reading. From the graph, the percentage of Phosphorus removal for $\mathrm{pH} 9.77$ is $99.54 \%$, while for $\mathrm{pH} 8.68$ the Phosphorus removal is $76.92 \%, 74.94 \%$ Phosphorus removal for $\mathrm{pH} 7.59$, then for $\mathrm{pH} 7.34$ the Phosphorus removal is $69.91 \%$ and finally the removal of Phosphorus for $\mathrm{pH} 6.92$ is $67.60 \%$. It was shown that higher the $\mathrm{pH}$, greater the efficiency percentage of Phosphorus removal. This is similar with Ahmad et al., 2017, for $\mathrm{pH} 9$ the percentage of Phosphorus removal is $98 \%$ in unaerated system filter. This is due to precipitate formed as the results of the removal affecting certain surface be unreachable for further reaction. These precipitate form at the wall of VARCAF filter. This is true for unaerated system because for unaerated systems which allow precipitates to form. Mohan et al. [14], stated that the higher the $\mathrm{pH}$ value, the higher the calcium content. Thus, the higher the calcium content, the higher the ability of the material to remove phosphorus.

On the other hand, Nasir [4] obtained the optimum $\mathrm{pH}$ value for effective removal of Phosphorus of $80 \%$ by using steel slag at $\mathrm{pH}$ 9.40 as an alkali. This is because steel slag also has higher calcium content and alkalinity. It shows that $\mathrm{pH}$ which is in alkali stage having process of precipitation which is can influence in removal of Phosphorus. Next, the effective removal of Phosphorus by using opoka as filter is at $\mathrm{pH} 12.60$. Opoka is siliceous sedimentary rock was deposited in the Mesozoic era. In contrast to limestone that is crystalline, Opoka is amorphous in its structure, making it highly porous. This material, from south-eastern Poland, and it also composed of $50 \%$ calcium carbonate $\left(\mathrm{CaCO}_{3}\right), 40 \%$ aluminium $(\mathrm{Al})$, iron $(\mathrm{Fe})$ and other oxides [15].

The removal of phosphorus by sand media was obtained the effective removal at stage alkali which is 7.8-9.5. In sand, phosphorus was bounded to the media due to consequence of adsorption and precipitation reactions with calcium $(\mathrm{Ca})$, aluminium $(\mathrm{Al})$ and iron (Fe). Besides, regarding to [11], the alkaline $\mathrm{pH}$ was help the cement release more $\mathrm{Ca}^{2+}$ ions into solution to react with phosphate causing precipitation of $\mathrm{Ca}_{3}\left(\mathrm{PO}_{4}\right)_{2}$. The equation can be seen as equation 1.0 below. The increase in $\mathrm{P}$ removal above $\mathrm{pH} 9$ could be due to a similar mechanism but from formation of $\mathrm{OH}$ enriched complexes precipitating calcium phosphate. $\mathrm{pH}$ levels greater than 6 , the reactions are a combination of physical adsorption to iron and aluminium oxides and precipitation as sparingly soluble calcium phosphates [16].

$\mathrm{Ca}^{2+}+3 \mathrm{PO}_{4} \rightarrow \mathrm{Ca}_{3}\left(\mathrm{PO}_{4}\right)_{2}$

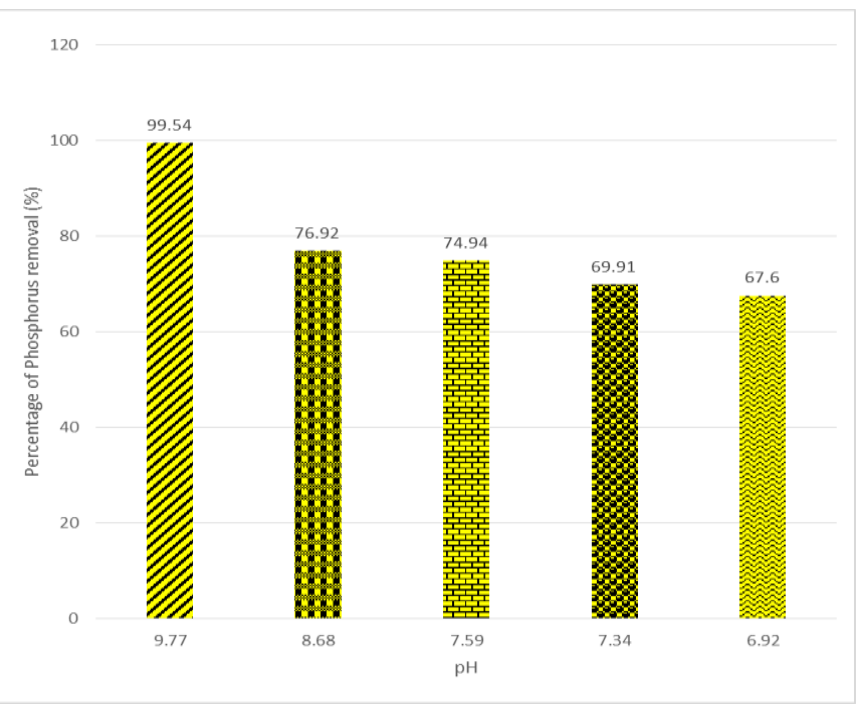

Fig. 7: Graph of percentage of Phosphorus removal versus pH reading

\section{Conclusion}

This study showed the higher percentage of removal of Phosphorus at lower concentration synthetic wastewater which is $10 \mathrm{mg} / \mathrm{L}$ is $99.54 \%$ which is RCA size $5 \mathrm{~mm}$ to $10 \mathrm{~mm}$ and it was proved that RCA is one of the absorbents that is good efficiency for removal of phosphorus.

\section{Acknowledgement}

The authors gratefully to acknowledge the Ministry of Education and Universiti Tun Hussein Onn Malaysia for providing the financial support through the Fundamental Research Grant Scheme (1618).

\section{References}

[1] Rozari PD, Greenway M \& Hanandeh A (2016), Phosphorus removal from secondary sewage and septage using sand media amended with biochar in constructed wetland mesocosms. Science of Total Environment 3, 123-133.

[2] Ayaz SC, Aktas O, Findik N \& Akca L (2012), Phosphorus removal and effect of Adsorbent type in a constructed wetland system. Journal of Environmental Engineering, 37.

[3] Zuo M, Renman G, Gustafsson JP \& Renman A (2015), Phosphorus removal performance and speciation in virgin and modified argon oxygen decarburisation slag designed for wastewater treatment

[4] Nasir NN, (2016). Effect Of pH and Density Metal Oxide on Removal of Phosphorus Using The Filter System Vertical Steel Slag.

[5] Johansson L (2013), Substrates for phosphorus removal potentia benefit for wastewater treatment. Water resources 40, 23-36. 
[6] Ahmad, SZN, Hamdan R \& Wan Mohamed WA (2017), Comparisons Study Of Phosphate Removal In Unaerated And Aerated Steel Slag Filter System. Jurnal Teknologi.

[7] Hamdan R \& Mara D (2013), Study of in-filter phosphorus removal mechanisms in an aerated blast furnace slag. International Journal of Research in Engineering and Technology, 2000.

[8] Adnan, SH, Hamdan R \& Yassin NIM, (2016), Removal of phosphorus from synthetic wastewater using recycled concrete aggregates as filter media. 2nd International Conference on Science, Technology and Social Science 2016.

[9] William D \& Swanson L (2011), Measuring the effect of zero lower bounded on medium and longer term interest rate. Working paper series.

[10] Wood RB \& Mc Atamney CF (2016), Constructed wetlands for wastewater treatment: the use of laterite in the bed medium in phosphorus and heavy metal removal. Hydrobiologial 340, 323-331.

[11] Yihuan D \& Andrew W (2018), Mechanism of phosphorus by recycled crush aggregate. International Journal of Environmental Research and Public Health.

[12] Chazarenz M, Surasyh H \& Deskon S (2017), Biological phosphorus removal process for wastewater treatment. International Conference of Science, 27

[13] Peavy H (2001), Phosphorus Sorption by Aggregates produced in the United States (2nd ed.).

[14] Mohan D, Sarswat A, Ok YS, Charles U \& Pittman J (2014), Organic and inorganic contaminants removal from water with biochar, a renewable, low cost and sustainable adsorbent - a critical review. Bioresource Technolpgy 160, 191-202.

[15] Behera M, Bhattacharya S \& Minocha A (2014), Recycled Aggregate from $\mathrm{C} \& \mathrm{D}$ waste and its use in concrete. Construction and building material 68

[16] Vohla C, Kõiv M \& Mander Ü (2016), Filter Materials for Phosphorus Removal from Wastewater in Treatment Wetlands - a Review, (January 2011). http://doi.org/10.1016/j.ecoleng.2009.08.003. 